Borschev, V. \& Partee, B. H. 2001

Genitive Modifiers, Sorts, and Metonymy

Nordic Journal of Linguistics 24,2

\begin{abstract}
Our long-term goal is to contribute to the integration of formal and lexical semantics. O ur more immediate theoretical starting point is the idea of "text as theory", within a model-theoretic semantic framework. We describe a set of empirical problems in the domain of genitive modifiers which offer a challenge to theories of the integration of lexical, compositional, and contextual information. After sketching a solution, we raise the issue of metonymy in the interpretation of genitives, and examine the role of sortal information in the specification of underspecified meanings and in processes of typeshifting and sort-shifting, including metonymy.
\end{abstract}

Vladimir Borschev and Barbara H. Partee

50 Hobart Lane

Amherst, MA 01002-1321

USA 


\title{
Genitive Modifiers, Sorts, and Metonymy ${ }^{1}$
}

\author{
Vladimir Borschev, VINITI, Russian Academy of Sciences \\ Barbara H. Partee, University of Massachusetts, Amherst \\ borschev@online.ru, partee@ linguist.umass.edu
}

\section{General background.}

The present paper is set in the context of long-standing concerns with ontology in the foundations of model-theoretic semantics. The shift from attempts to make use of first-order predicate logic in linguistic semantics to the use of more powerful logics accompanied by more richer model structures has brought with it the need for a correspondingly more sophisticated approach to the ontological choices to be made in any formal semantic theory.

Predicate logic has a very simple ontology: entities, truth values, and n-ary relations. Montague's intensional logic (Montague 1973), on the other hand, uses a model theory that includes (unstructured domains of) entities, possible worlds, and times. The model structure is further enriched with functional and intensional types.

The study of questions concerning the appropriate model structures for a formal semantics of natural languages has been called "Natural language metaphysics" (Bach 1986a, 1986b). O ne example of an important innovation in this area is the proposal by Godehard Link for a semilattice structure in the entity domain (Link 1983) as a crucial ingredient in the account of plurals and mass terms. Recent work concerning a proposed event argument in the argument structure of many or all verbs (see, for example, Kratzer 1994, 1995, Parsons 1985, 1990, Rothstein 1998, Tenny \& Pustejovsky 2000) has shown even more clearly how important and how difficult the decisions about underlying model structure can be in the overall semantic enterprise.

In Russian lexical semantics the corresponding area of concern is formulated as the investigation of the naivnaja kartina mira 'naïve picture of the world' (A presjan 1974, 1986, Apresjan et al. 1969). Both the western and the Russian approaches strive, albeit often using different tools and different kinds of argumentation, to identify presuppositions about the nature of the world (the model structure) implicit in human language, whether in the structure of the lexicon or in the the semantics of structural elements such as tense and aspect or the subjunctive mood.

O ur long-term goal is to contribute to the smooth integration of formal and lexical semantics, including the convergence of the investigations of natural language metaphysics with investigations into naivnaja kartina mira. Our focus in this paper is the role of sortal information in the specification of underspecified meanings and in processes of type-shifting and sort-shifting, including metonymy.

\footnotetext{
${ }^{1}$ The authors wish to thank many colleagues for suggestions and discussion, especially Carl Vikner, Per Anker Jensen, other participants in the OntoQuery workshop, Elena Paducheva, and Ekaterina Rakhilina. Parts of this material were presented by one or both authors in graduate courses in Leipzig, Potsdam, Kolding, Moscow, and Prague, in a reading group at UMass Amherst, and in lectures in Berlin, Munich, Kleinwalsertal, Bloomington, Swarthmore, and Tel Aviv, at ESCOL 1999 and at the conference "Approaching the Grammar of Adjuncts" in Oslo. We are grateful to members of those audiences for useful suggestions. The first parts of this paper overlap with parts of Borschev and Partee (1999b) and Partee and Borschev (2000).

This material is based upon work supported by the National Science Foundation under Grant No. BCS-9905748.
} 
The structure of the paper is as follows. In Section 1 we present a brief sketch of our theoretical starting point, the idea of "text as theory", working within a modeltheoretic semantic framework. In Section 2 we describe a set of empirical problems in the domain of genitive modifiers which offer a challenge to any theory of the integration of lexical, compositional, and contextual information. In Section 3 we present our solution as developed in Partee and Borschev (1998, 2000), partly in tandem with the work of Vikner and Jensen (1999). The issue of metonymy in the interpretation of genitives is the subject of Section 4, which draws in part on work reported in Borschev and Partee (1999b). Related work by Dölling, Hobbs, and others who have worked on the development specific systems of sortal information and on metonymy as sortal coercion is described briefly in the final Section 5.

\section{The framework: text as a theory.}

O ur framework is the integration of the compositional "semantics of syntax" given by formal semantics with a lexical semantics largely in the style of the Moscow school.

In formal semantics a sentence is represented by a formula of a metalanguage such as Montague's intensional logic in which lexical items are primitives. The Moscow semantic school represents lexical meanings as dictionary definitions (necessary and sufficient conditions). In recent work (Borschev \& Partee 1998, Partee \& Borschev 1998), we have proposed to represent lexical information in the form of sets of meaning postulates, which makes it possible to integrate lexical semantics with the compositional "semantics of syntax" given by formal semantics. We believe the use of meaning postulates is consistent with the core of actual Moscow school practice.

Working compositionally, combining formulas of syntactic constructions with lexical postulates (and in principle with formulas representing various kinds of contextual information), we obtain in the result a set of formulas representing a sentence or a text.

Thus, we represent a sentence or a text as a theory consisting of different sorts of formulas, i.e. different sorts of axioms and their entailments. By "theory" here, we mean the set of axioms from various sources plus the consequences that can be drawn from these axioms, which together constitute the interpretation of such a sentence in a given context. Such a theory (see Borschev 1996) characterizes the class of all models that are consistent with the content of the given text, or of the text together with certain aspects of its context, if the theory includes axioms representing contextual information. The most general structure (features and constraints) of such models represent what the Moscow School calls "naivnaja kartina mira" 'the naive picture of the world' (Apresjan 1994), and what formal semanticists, following Bach (1986a, 1986b), call Natural Language Metaphysics.

On our model-theoretic perspective, all of the "axioms" from all of the different sources jointly constrain the possible models, and their joint effects may account for phenomena ranging from ambiguity reduction to meaning-shift phenomena such as "coercion". It will undoubtedly turn out that the mechanism of axiom interaction is rather complicated, and may include modifications (shifts) in some axioms in the context of the others (Lascarides \& Asher 1993).

In this report we illustrate one possible mechanism of such interactions, sortshifting and type-shifting operators. These operators are similar to operators considered by Jensen and Vikner (Jensen \& Vikner 1994, Vikner \& Jensen 1999), differing in the extent to which our operators are based on sort descriptions. 


\section{The problem of the semantics of genitives.}

O ur topic for illustrating our concerns is the semantics of the Russian G enitive Modifier (G M) Construction exemplified in (1). Each phrase has a head noun (head N), here in the nominative, followed by a noun phrase (often just a single word, since Russian does not have articles) in the genitive, which we will call the GEN NP.

(1)

(a)
ljubitel'
košek
lover-NO M-SG cat-GEN-PL
'lover of cats, cat-lover'
rost celoveka
height-NOM-SG man-GEN-SG
'height of the/ a man'

(b)

nožka stola
leg-NOM-SG table-G EN-SG
leg of the table, table leg'
stakan moloka
glass-NOM-SG milk-GEN-SG
'glass of milk'

portret Peti

portrait-NOM-SG Petja-GEN

'picture of Petja'

(c) sobaka dočri

dog-NOM-SG daughter-GEN-SG

'the daughter's dog'

$$
\begin{aligned}
& \text { nebo Andreja Bolkonskogo } \\
& \text { sky-NOM-SG Andrej-GEN Bolkonsky-GEN } \\
& \text { 'Andrej Bolkonsky's sky' }
\end{aligned}
$$

Roughly speaking, the construction describes an entity or entities of a sort determined by the head noun, described as standing in a certain relation to some other entity or entities denoted by the genitive NP. Similar constructions exist in many languages.

\subsection{The diversity of genitive relations.}

One of the basic problems concerning this construction is the diversity of relations and their sources. Consider the examples above. In the examples in (1a), the relation is expressed by the head noun (but every time in a different way). The first entity (the first argument of the relation) is also denoted by the head noun and the (second) argument of the relation - by GEN NP.

In the examples in (1b) the picture is more complicated. The head nouns here are not "relational". They denote classes of entities and can be used without genitive (or adjectives). But relations (used in constructions) can be extracted from their meaning. In a way, the "normal" meaning of these nouns often becomes shifted in these constructions. (Note: we are quite uncertain whether no: ka belongs in group (1a) or (1b); here we are treating it as a one-place predicate which is easily shiftable to a two-place relation.) 
In the examples in (1c) with head nouns that do not (normally) express relations, we need to explain where the "genitive relation" comes from. Sometimes, as in nebo Andreja Bolkonskogo 'Andrej Bolkonsky's sky', the relation is unclear without a strong supporting context (such as the description in War and Peace of the sky seen by the wounded Bolkonsky). Note that strong context can overrule normal relational usage of head noun (jubovniki Rodena - 'Rodin's lovers'). In the case of sobaka dočeri 'the daughter's dog', the "default" choice of 'ownership' or 'possession' seems to come from 'typical preferences' of the genitive construction itself.

\subsection{One or many constructions?}

O ur thesis corresponds to the traditional description of the Russian GM construction. We think that this construction has a uniform semantic interpretation. We argue that in the semantics of the GM construction, the GEN NP is always of a semantic type which "looks for" a relational interpretation of the head N. The diversity of interpretations reflects the diversity of ways in which the head $\mathrm{N}$ may be or may come to be construed as involving a relation. The lexical semantics may supply a relation through the sortal information concerning the head $\mathrm{N}$. When it does not, then lexical semantics, background, and contextual information interact in facilitating a shift of the sense of the head $\mathrm{N}$ to an appropriate relational interpretation.

In recent work of Jensen and Vikner (Jensen \& Vikner 1994, Vikner \& Jensen 1999) and in our own recent work (Borschev \& Partee 1999a, 1999b, Partee 1997) there is an ongoing discussion of whether and how possessive constructions in D anish and English must be split into two, depending on whether the head $\mathrm{N}$ is relational or not. Jensen and Vikner have made innovative use of lexical semantics schemes proposed by Pustejovsky. In Borschev and Partee (1999a, 1999b), we basically followed Jensen and Vikner (Jensen \& Vikner 1994, Vikner \& Jensen 1999) in advocating a single rule plus coerced type-shifting, and we still believe that their approach is correct for the Russian genitive. $^{2}$

One part of our task is to understand the seemingly non-uniform contribution of lexical semantics to the interpretation. Much of the groundwork has been laid in work of Knorina ((Borschev \& Knorina 1990, Knorina 1985, 1988, 1989, 1990, 1996)), who examined how differences in the fine-grained semantic sorts of the head $\mathrm{N}$ contribute to the determination of the particular relations that are evoked in the interpretation of the construction. The notion of semantic sorts, including relational classification into events and their participants, artifacts and their creators, images and imaged-objects, parts and wholes, etc., was argued by Knorina to underlie not only many details of the GM interpretation but also to be an essential part of the lexical semantics of each noun and to contribute centrally to metaphorical extensions of lexical and constructional meanings, including that of the GM construction. This conception of the role of the sortal classification of nouns, discussed below and in Borschev and Partee (1999b), is also related to the work of Jackendoff (1997) and Pustejovsky $(1993,1995)$.

\section{A unified analysis of the Russian genitive modifier construction}

For the fundamental problem of providing a unified semantics for a construction whose meanings seem so diverse, the Russian G M construction is similar to the

\footnotetext{
${ }^{2}$ In recent work we have begun to question whether the 'uniform genitive construction with coercion' approach is correct for English: see Partee and Borschev (2000, 2001).
} 
possessive construction in English and in Danish, discussed and debated in the works by Jensen and Vikner and by Borschev and Partee mentioned above. The main features of the resulting unified analysis are as follows.

With the genitive construction, the head $\mathrm{N}$ or N-bar is always construed relationally, as being of type $\langle\mathrm{e},\langle\underline{\mathrm{e}}, \mathrm{t}\rangle>$; this is the heart of the unified interpretation. But it is to be emphasized that relational Ns are still Ns; both simple and relational Ns characterize the entities filling their "referential role" as belonging to a certain "sort". In the type symbols we underline the type-e position corresponding to the "referential role", adapting the practice of Williams (1981). Relational Ns differ from simple sortal Ns in having an additional argument place; they describe their referents not only (and sometimes not primarily) as being of a certain "sort" but as standing in a certain relation to some other entity or entities. Using "Thing" as a place-holder for a sortal property and "Related-to" as a place-holder for a relation, the basic scheme of the interpretation of a simple sortal $\mathrm{N}$ is as in (2a), and that of a relational $\mathrm{N}$ as in (2b).
(2)
a. $\quad \lambda x[$ Thing $(x)]$
b. $\quad \lambda y \lambda x[\operatorname{Thing}(x) \&$ Related-to- $y(x)]$

For different relational nouns, and for whole families of relational nouns of different sorts, there are different distributions of lexical information concerning the "sortal part" and the "relational part" of their meaning. These include important differences about how much is explicit in the lexicon and how much often comes from stereotypically associated information or from the context. We illustrate these remarks briefly here. More detailed treatment of some particular examples will be considered below.

A basic sortal $\mathrm{N}$, type $<\underline{e}, \mathrm{t}>$, has a referential role and a characterizing property. In (3) below, where we treat no ̌ka as basically a sortal noun, the referential role is filled by $x$, and the characterizing property is indicated as nožka.

$$
\text { nožka in type < }, \mathrm{e}, \mathrm{t}>\quad \lambda x[\operatorname{nožka}(x)] \quad \text { 'leg' }
$$

A relational N's referential role is characterized as one term of a relation. We can represent a directly relational $\mathrm{N}$ as in (4a) (the more "standard" representation) or, following the schema of (2b), as in (4b); an indirectly relational $\mathrm{N}$ is represented as in (4c).
a. ljubitel' in type $<\mathrm{e},<\underline{\mathrm{e}}, \mathrm{t}>>$ :
$\lambda y \lambda x\left[\operatorname{ljubitel}^{\prime}(y)(x)\right]$
'lover'
b. ljubitel' $<\mathrm{e},<\underline{\mathrm{e}}, \mathrm{t}>>$ : $\lambda y \lambda x\left[\operatorname{person}(x) \&\right.$ ljubitel' $\left.^{\prime}(y)(x)\right]$ 'lover'
c. no ̌̌ka in type $<\mathrm{e},<\underline{\mathrm{e}}, \mathrm{t}>>$ :
$\lambda y \lambda x[\operatorname{nožka}(x) \&$ Part-of $(y)(x)]$
'leg'

The whole GM construction then picks out an entity or entities (of a sort determined by the head $\mathrm{N}$ ), described as standing in a certain relation to some other entity or entities denoted by the GEN NP. The semantic "sort" of the head N often dictates a "most easily available" choice of relation, as discussed in Knorina (1988), Borschev and Knorina (1990), Pustejovsky (1995), Jensen and Vikner (1994). ${ }^{3}$ Thus the classification of nožka as a 'furniture part' makes the relation 'Part of' saliently accessible.

\footnotetext{
${ }^{3}$ Jensen and Vikner (Jensen \& Vikner 1994) argue, and we agree, that part-whole information belongs in the lexical entry of the part, not that of the whole, as proposed by Pustejovsky; it is the part-nouns that are, or shift to become, relational nouns, not the whole-nouns.
} 
In the cases where context contributes a salient relation, like the nebo case discussed earlier, we take the context to be locally enriching the normal dictionary 'theory' of nebo. This is our way of integrating the "contextual relation" cases into Jensen and Vikner's approach on which the head $\mathrm{N}$ is always the locus of the relation in the GM construction. So we represent the nebo example as in (5).

$$
\text { nebo in type }<e,<\underline{e}, \mathrm{t}>>: \quad \quad \lambda y \lambda x[\text { nebo }(x) \& \text { seen-by }(y)(x)]
$$

The rule for interpreting a GEN NP is simple and uniform, as illustrated in (6):

$$
\text { GEN NP interpretation: stola: } \lambda R[R(\mathbf{s t o l})]
$$

The resulting GEN NP meaning is partly modifier-like and partly argument-like: it is modifier-like in that it combines with an $\mathrm{N}$ meaning to give a new $\mathrm{N}$ meaning, but it is not a normal endocentric modifier, since it combines with an $\mathrm{N}$ meaning of type $<e,<e, t>>$ to give a new N meaning of type $<\underline{e}, t>$. And it does this by "filling in" the internal argument role of the relational $\mathrm{N}$ meaning with the value of the NP in the GEN NP.

The rule for combining a GEN NP with a relational $\mathrm{N}$ is just function-argument application. The application of the GEN NP stola (see (6)) to the relational N no žka (see $(4 c))$ is as shown in (7).

$$
\begin{gathered}
\lambda R[R(\text { stol })]\left(\lambda_{y} \lambda x[\operatorname{nožka}(x) \& \text { Part- of }(y)(x)]\right) \\
=\lambda_{y} \lambda_{x}[\text { nozka }(x) \& \text { Part- of }(y)(x)](\text { stol }) \\
=\lambda_{x}[\operatorname{nožka}(x) \& \text { Part-of }(\text { stol })(x)]
\end{gathered}
$$

The formulas given above are rather schematic, but indicate the basic ideas of our approach.

\section{Metonymy. Sorts of head nouns and the semantics of the GM construction.}

The interpretation of genitives often involves metonymy of various kinds. Here we consider several examples, beginning with some informal discussion.

\subsection{Containers.}

In the examples in (8) below, the head nouns denote containers. We take container to be a sort of entity. We will not define it nor justify its existence, but consider some examples, whose syntactic structure is identical to that of the phrases in (1).

(8)
Stakan moloka
jašick jablok
mašina drov
'glass of milk'
'box of apples'
'truck of wood'

Let us describe the basic meaning of stakan as stakan1, with semantic type <e,t>, by giving some rough and informal meaning postulates:

(9) stakan1 is a physical object, artifact, container. It is a vessel for liquids and other substances. People use it to drink from. 
As for every word whose sort is container, there exists a standard metonymy: stakan molok $a$ is a quantity of milk, contained in a glass. This result of a metonymic shift, which we denote by stakan2, is a relational noun. Its semantic type is $\langle e,<e, t>>$. We can try to define its meaning in terms of that of the basic stakan 1 in the following way:

\section{stakan2 is a quantity of some substance filling some stakan1.}

Quantity and container are two different sorts which are incompatible: it is impossible to be a glass and milk at the same time. But the metonymic "origin" of stakan2 makes possible sentences of the kind: On yypil stakan moloka, kotoryj stojal na stole 'He drank a glass of milk which was standing on the table'. In this sentence stakan seems to belong to a kind of "paired sort" (something like a Cartesian product for sorts; Pustejovsky (1995) used the term dotted type).

Note that it is possible to speak about stakan3, as a measure corresponding to a prototypical stakan1. Syntactically stakan3 does not differ from stakan2 and they have the same semantic type, $<\mathrm{e},<\mathrm{e}, \mathrm{t}>>$. But it is a different sort. Examples can be found in cookbooks: add two glasses (cups) of milk, three eggs...

The noun mašina 'car' or 'truck' is slightly more complex than stakan. If it is a truck, it has kurov 'a back part of a truck' which is a container. So masina drov 'a truck of wood' is a result of a double metonymic shift: from a whole to a part which is a container, and from a container to a quantity. Such a "two step shift" makes it more difficult to have the "pair" of the basic meaning and a quantity in the same sentence; (11) is at least very difficult to interpret as intended, if not ungrammatical.

(?) Za zimu on š̌eg mašinu drov, kotoraja stojala u nego vo dvore.

'D uring the winter he burned the truck[ful] of wood which stood in his courtyard'

The word sljapa 'hat' is even more interesting. Consider the sentence: On prines polnuju sljapu gribov 'He brought a full hat of mushrooms'. S'japa is not a container; and the dictionary entry should not ascribe this sort to it. But the form of hat is similar to that of a container, and we understand that in the described situation it was used as a container. So the word sljapa in this sentence is understood, by a shift that is supported by the context, as a container. It is of interest to note that without the adjective polnuju 'full' the sentence does not sound good to the Russian ear, whereas with the adjective present, the intended context is readily accommodated. This adjective is most naturally interpreted as a property of a container and, in this way, helps to coerce the shift of the word sljapa to the sort container.

\subsection{Possible schemes of formalization.}

How should we formalize the range of meanings of nouns like stakan described above? The first possibility is to put into the dictionary definition of every word the list of all sorts to which the word belongs, and to write down all the different meanings of the word together with statements relating these meaning to each other.

Thus, for the entry stakan 2 we could have in the dictionary the formula: 
(12) $\quad$ a. $\quad \operatorname{stakan2}(y)(x) \Leftrightarrow \operatorname{substance}(y) \&$ quantity(y)(x) \& $\exists z(\operatorname{stakan1}(z) \&$ or equivalently, fills $(z)(x))$

b. $\quad$ stakan2 $=\lambda y \lambda x[\operatorname{substance}(y) \&$ quantity $(y)(x) \& \exists z(\operatorname{stakan} 1(z) \&$ fills(z)(x))]

We consider the formulas (12a) and (12b) as an approximate translation of the "definition" (10). In them we have used the constants substance and quantity for sorts and the "normal" constant fills.

Then we can get the expression for the whole construction stakan moloka 'glass of milk' (interpreted as a 'quantity of milk') in the following way. The function $\lambda \boldsymbol{R}[\lambda \boldsymbol{x}[\boldsymbol{R}(\mathbf{m o l o k o})(\boldsymbol{x})]]$ will correspond to GEN NP, in this case the word moloka 'milkGEN-SG'. Applying this function to the expression for stakan2 (the right side of the formula (12b)), we get the expression for the whole construction stakan moloka in (13).

(13) $\lambda x[\operatorname{substance}($ moloko) \& quantity(moloko)(x) \& $\exists z(\operatorname{stakan1}(z) \&$ fills(z)(x))]

And for stakan3 (stakan as a measure) we could have the formula (14), where STAKAN is a measure of volume equal to the volume of prototypical stakan (for example, 200ml).

$$
\text { stakan3(y)(x) } \Leftrightarrow \operatorname{substance}(y) \& \text { quantity }(y)(x) \&(\operatorname{volume}(x)=\text { STAKAN })
$$

But if we proceed in this way of "multiplying entities", we would be forced to write down analogous formulas for all containers: boxes, jars etc. And, what is worse, we would have to write down lexical entries for the "container" sense of words like sljapa 'hat'.

It would be better to describe the lexical meaning of the sort container, or in our terms, to write down the theory of this sort ${ }^{4}$. We give below a semiformal scheme of such a theory.

\section{Container(y)(x)}

sort - physical object $\boldsymbol{X}$

usage - $\boldsymbol{x}$ can be used to hold/ keep substances of the sort $\boldsymbol{y}$

form $-\boldsymbol{x}$ has an inner part and when it is used to keep a substance $\boldsymbol{y}, \boldsymbol{y}$ is inside of $\boldsymbol{X}$

volume of $\boldsymbol{x}$-the volume of $\boldsymbol{x}^{\prime}$ s inner part and so the volume of the substance that $\boldsymbol{x}$ can contain.

Such a theory will allow us to introduce the shift-operator $\mathbf{Q}$ uant, generating for all words which can be considered as denoting containers (having the sort container) expressions similar to the expression for stakan2:

\section{(16) The shift-operator Q uant:}

Quant $(P)=\lambda y \lambda x[\operatorname{substance}(y) \&$ quantity $(y)(x) \& \exists z(P(z) \&$ fills $(z)(x))]$ domain restriction: $\boldsymbol{P}$ belongs to the sort container

\footnotetext{
${ }^{4}$ This approach is similar to use of abstract data types in computer science.
} 
output specification: $\mathbf{Q}$ uant $(\boldsymbol{P})$ belongs to the sort quantity

Then, if the word belongs by its dictionary meaning to the sort container (like stakan) or can be understood as a container in a specific context (like sljapa), we can apply this operator to it and get an expression which corresponds to the result of metonymic shift of this word to the sort quantity. For example, if $\boldsymbol{P}$ is stakan (in this case we do not need to multiply stakan's), we will get expression (17) for stakan shifted to the sort quantity:

\section{(17) $\lambda y \lambda x[\operatorname{substance}(y) \&$ quantity(y)(x) \& $\exists z(\operatorname{stakan1}(z) \&$ fills-in(z)(x))].}

Let us consider one more example. Portret 'picture', statuja 'statue', fotografija 'photograph' - all these words belong to at least three sorts: physical object, image and proizvedenie 'creation'. For example, for the word portret we could introduce three constants: portret1, portret2 and portret3: the first, non-relational, of the type physical object, and the other two relational, of the type $<\mathrm{e},<\mathrm{e}, \mathrm{t}>>$. The last two can be defined by the following equations:

$$
\begin{array}{ll}
\text { a. } & \text { portret2 }=\lambda y \lambda x[\operatorname{portret} 1(x) \& \text { image }(y)(x)] \\
\text { b. } & \text { portret3 }=\lambda y \lambda x[\operatorname{portret1}(x) \& \operatorname{proizvedenie}(y)(x)]
\end{array}
$$

But again, not to multiply entities, it is better to introduce abstract objects image and proizvedenie and construct corresponding shift operators similar to the operator $\mathbf{Q}$ uant.

\subsection{Summary: conclusions about the Genitive Modifier construction and metonymy.}

We think that $\mathrm{G}$ enitive Modifier Construction has a uniform semantic interpretation. We build it integrating the formula of a construction with "lexical formulas" of parts. O ur description continues the work of Partee and of Jensen and Vikner. We also build on L. Knorina's work on sortal classification of head nouns. Using sortal characteristics of head nouns we describe the relations they supply. D escriptions of sorts are in a way similar to qualia structure of Pustejovsky. The possible metonymic shifts are defined on sorts. By describing these shifts for an abstract object representing a sort, we generate the different meanings for any noun which belongs to that sort, including the relational senses of the noun.

\section{Related work on metonymy as coerced sort-shifting.}

\subsection{Semantic sorts.}

Montague grammar classically limited itself to compositional semantic issues, and considered lexical distinctions only down to the level of semantic types (e, <e,t>, etc.). Early work such as Michael Bennett's work on plurals (Bennett 1974) used distinctions in type to capture semantic distinctions which have later been argued (see especially Link 1983) to be better captured as distinctions in sort within a given type.

In Bennett's analysis, plural predicates were seen as predicates of groups, and groups were analyzed as sets of entities, hence of type $<e, t>$; a singular NP was of type $<<e, t>, t>$, while a semantically plural NP was of type $<<<e, t>, t>, t>$. This analysis required a corresponding multiplicity of types for adjectives and verbs, and therefore also for adverbials, and therefore also for prepositions. Because the type multiplicity was 
systematic, it was not a fatal drawback, but it can be argued that an approach like Link's, which treats "plural entities" as a different sort within type e, provides a better fit with the structure of natural languages like English. (Link's work also makes possible a closer correspondence between mass nouns and plural nouns, which is a further advantage.)

Johannes Dölling, inspired by Bierwisch's "two-level semantics" ((Bierwisch \& Schreuder 1992), argues in several papers (Dölling 1992a, 1992b, 1993, 1995, 1997) that there are several more fine-grained sorts that need to be distinguished besides just individuals vs. groups, and that 'plural individuals' should not be simply identified with 'groups'. In Dölling (1992a), he argues for the following distinct sorts, which have overlapping groupings into larger sorts:

Figure 1:

\begin{tabular}{|l|l|l|l|l|l|}
\hline INDIV & INDIV & INDIV & INDIV & MASS & MASS \\
\hline-- & -- & COLLECTIVE & COLLECTIVE & COLLECTIVE & -- \\
\hline THINGS & INSTITUTIONS & GROUPS & CONFIGURATIONS & AGGREGATES & STUFF \\
\hline D og & school & team & Pile & furniture & Gold \\
\hline Student & university & family & Collection & clothing & Coffee \\
\hline
\end{tabular}

The arguments for these distinctions include (a) systematic selectional restrictions among classes of verbs, adjectives, etc.; (b) systematic polysemy and sort-shifting that relates these sorts; and (c) consistency with commonsense ontological distinctions for which there are various kinds of evidence.

The largest sort, for all the entities above and also for "kinds", is U ("entity"); $U$ is divided into "objects" $(\mathrm{O})$ and "kinds of objects" $\mathrm{K}$. The objects are further subdivided into the sorts in the chart above: "things" DO, "institutions" IO, "groups" GO, "configurations" CO, "aggregates" AO, and "stuff" SO . (There are corresponding subsorts of kinds, DK, IK, etc.) The domain of "persons" PS is a subdomain of the domain of the domain of things DO.

For each sort, there are axioms that characterize its internal part-whole (mereological) structure (basic axioms for the part-whole relation plus axioms relating to 'atomicity', the existence of sum-formation, etc.). And there are axioms that describe systematic relationships among the domains: the relation of each object-sort to its corresponding kind-sort, the relation of "constitution" that links things, groups, and aggregates to the things or stuff they are made up of.

For institutions, it is clear on the one hand that they have some special relation(s) to one or more persons - their supporters, representatives, employees, or the like. On the other hand, what the particular relationship is not constant for different nouns in this class, and may be more "empirical" than "lexical". This is typical of a kind of problem encountered in this area: being able to say for a class of lexical items that an important relation of a certain kind exists, but not being able to say just as a matter of knowledge of language what that relation is. To represent such relations, we can either use a constant whose interpretation is left rather vague, like $\mathrm{REP}_{\mathrm{IO}}$ in Dölling (1992a) or CO NT $\mathrm{I}$ in Dölling (1995), or one might make use of context-dependent variables with some lexically specified constraints on their values. In any case, non-linguistic knowledge will be involved in many instances of interpreting the given constant or variable, as in the case of the metonymically shifted meanings of newspaper and school in the examples in (19).

(19) a. The newspaper telephoned today.

b. My school will be playing a championship match tomorrow. 
C. That school admits very few foreign students.

\subsection{Selectional restrictions} variable:

Dölling introduces a notation for restricting the range of values assigned to a

(20) If $\alpha$ is a variable of type $a$ and $\Phi$ is a predicate of type $<a, t>$, then $\alpha$ : $\Phi \alpha$ is a restricted variable of type $a$.

(Read " $x: P x^{\prime \prime}$ as " $x$ with the restriction that $P x$ ")

The restriction operator is very useful for specifying the presuppositions of various predicates; see, for instance, its use in Heim and Kratzer (1998). O ne important use is to express sortal constraints that a word or phrase imposes on its arguments:

(21) $[(\lambda \alpha: \Phi \alpha)[\Psi]]$ denotes a function whose domain is restricted to those entities $d$ of the type of $\alpha$ which are such that $\Phi$ is true of $d$. Where defined, the function returns a value determined as usual by evaluating $\Psi$ with $d$ as the value for the variable $\alpha$. If $\Phi$ is not true of $d$, then the function is undefined for $d$. ("Presupposition failure.")

For example, widespread can only apply to kinds. Melt applies only to stuff. Stand on the table applies only to things. Have red hair and telephoned apply only to persons. Intransitive meet applies only to pluralities of persons (as indicated by the pluralized 'persons' sort ^^PS.)

(22) a. widespread: $(\lambda x: 0 \mathrm{~K} x)$ [WIDESPREAD $x]$

b. meet: $(\lambda x: \wedge P S x)[\operatorname{MEET} x]$

Hence sortal incorrectness is modeled as presupposition failure, which in turn is modeled as the failure of a function to be able to apply to the argument that is given to it, i.e. a failure of function-argument application.

(23) \#John is widespread. \#My cats are widespread. $\checkmark$ Cats are widespread. \#John met yesterday. $\checkmark$ John and I met yesterday.

\subsection{Coercion by selectional restriction.}

But violation of selectional restrictions does not always lead to anomaly; sometimes it leads to a coerced meaning shift, involving a shift in the sort of the noun. In (24a), the requirement that the subject of the verb telephone be human, together with the possibility of an appropriate shift for newspaper, discussed in more detail in section 5.4 below, leads to the likelihood of an interpretation in which a person who is a representative of the newspaper telephoned. In (24b), there is a possibility of interpreting the sentence as reporting the unremarkable fact that a particular copy of the newspaper has been sold. But if we are discussing the newspaper as a whole, and there is no salient copy that whose sale we might be talking about, there is a possible shift to the newspaper-producing-company as a 'corporate entity' that may be sold as a whole. Similarly, the examples in (25) involve different 'sorts' for the different construals of 
school, all imposed by the sortal restricitons of the verb phrase: institution with properties of an animate agent; physical building; group of people.

(24) a. The newspaper telephoned yesterday.

b. The newspaper has been sold.

(25) a. The school gave a large amount of money.

b. The school stands near a forest.

c. The school met.

Example (26) is ambiguous: it may be the material of the cup, or its contents, that is melting; both are presumably shifts, since melt applies to a substance rather than to an entity like a container.

(26) The cup is melting.

This is where the existence of axioms connecting the various sorts comes into play; they help to license the kinds of shifts that are actually systematically possible. The study of the possible interpretations of such sentences is one major kind of evidence for the existence and nature of sort-shifting operations.

The hypothesis that multiple 'chained' shifts become progressively harder to process means that such evidence that also help to determine which meanings are the most basic and which are derived by shifting.

Dölling argues (as does Krifka 1995) that nouns start out denoting kinds; but there is a natural shift shifting them 'down' to being predicates of things; and from there they can further shift to more specialized predicates of either individual things or pluralities of things. These are fully general shifts. More specific shifts include such things as shifts from an institution to a physical building that contains it, or from an institution to a group of people 'conventionally associated with it'. More specific still may be the shift from a noun interpreted as a predicate of entities which fall under the sort container to an interpretation as predicate of the contents of the container, as in one reading of The cup melted.

\subsection{Semantic operations of sort coencion.}

Dölling (1995) gives a number of "templates of sort coercion", highlighting systematic properties of a number of sort-coercing operations, some from the literature, and some newly proposed. Some of them contain variables that represent crucial parameters that have to be supplied by the context (analogous to the "free R" relation discussed in connection with possessives in Partee (1997), Partee and Borschev (1998, 2000)). Here D ölling distinguishes between the compositional semantic interpretation, which leaves free variables as variables, and the specified semantic representation, which uses world knowledge to fill in a value for any free variables.

\section{(27) The newspaper telephoned.}

Dölling derives the likely interpretation of (27) by a series of four steps (Dölling 1995, p.803). Initially, the noun newspaper starts out in the union of thing-kind and institution-kind. 
The first shift is "Instantiation", from kind to object. This shifted newspaper is now in the sort "thing" $\cup$ "institution".

The second shift is "Specification", from the union of sorts to just one sort; in this case, the result is the sort "Institution". entities.

The third shift is by the operation "Singular", differentiating singular and plural

The fourth shift is a specific operation labeled "SHIFT1", shifting from the institution to some person(s) associated with it by free relation $R$.

The compositional interpretation ends there, with a formula that can be loosely paraphrased as "There is a y which bears relation $\mathrm{R}$ to the unique institution which in the given context instantiates the kind 'newspaper'".

Then the "specified semantic interpretation" is obtained by using contextual knowledge to fix the relation R as "ASS" ("is/ are associated with").

O ne contrast between Dölling's approach and Pustejovsky's is that Pustejovsky looks for the basis of sortal coercions in the structure of the lexical entries, while Dölling looks for it in the structure of our commonsense knowledge of the ontological domains that underlie the sortal classification of lexical items. It seems to us that Dölling's approach has an advantage with respect to the problem of integrating linguistic and nonlinguistic sources of knowledge in disambiguation and shifting of lexical senses in context.

The difference between the approach to coerced shifting in Partee and Borschev (1998) and that in Jensen and Vikner (1994) is similar to the just-mentioned difference between Dölling and Pustejovsky. Partee and Borschev (1998), like D ölling, appeal to (but do not explicitly provide or describe) a richly structured background theory of ontological sorts and potential sort-shifting operations among them. We have assumed that sortal information in lexical entries will provide some of the bridging concepts allowing for the interaction of linguistic and non-linguistic "axioms" in the building up of the integrated "theory" of the interpretation of a sentence in context.

In recent works, the mutual influence of Borschev and Partee and Vikner and Jensen is becoming evident, as we have increasingly converged in recognizing the importance of both lexical and contextual factors and the need for a better-articulated theory of their interaction. D ölling's work gives a number of illustrations of how such an approach might work in some detail.

Like many linguists, we have relatively little expertise in the area of knowledge representation, but we do not doubt that questions about the structure of non-linguistic knowledge, while difficult and controversial, are of importance for the study of sorts and natural language ontology. There are several kinds of works we should mention as of potential importance in this area.

O ne problem which faces all attempts to account for the undeniable role of nonlinguistic knowledge, both in disambiguating among possible senses and in finding suitable ways to coerce meanings so that sortal conflicts can be resolved, is the problem that there is no apparent bound on the amount of commonsense or contextual knowledge that may be relevant to a coercion or a disambiguation. How do we choose what subset of the potentially infinitely many inferences that we could draw in a given situation to actually draw? This is the central issue addressed in (Hobbs et al. 1993) in their work on abduction. 
John got into the car and turned the key, but the engine didn't start.

How are the uniqueness presuppositions of the three definite descriptions satisfied? The apparent answer is that we readily accommodate the presupposition that John has or has access to a car, that when one gets into a car, there is a unique most salient key (the one that starts the car), and that a car has a unique engine. But these are just a few of many more inferences that could be drawn. Do we also draw the (available) inferences that there is a unique windshield, a unique rear-view mirror, a front seat and probably a back seat, and all the other things we know about cars and car-starting situations? Those inferences are available if we need them, but given the many further such possibilities, and the inferences that would follow from those inferences, it hardly seems likely that they are all actually carried out.

Abduction is characterized by Hobbs et al. as "inference to the best explanation". "The process of interpreting sentences in discourse can be viewed as the process of providing the best explanation of why the sentences would be true." (Hobbs et al. 1993, p.69)

So the hearer assumes that the sentence the speaker produces is true (or at least that the speaker intends it to be taken as true), and the choice of inferences is driven in part by a non-deductive search for axioms which taken together would make the sentence true. Consider, for example, a sentence such as (29).

\section{(29) The Boston office called.}

For interpreting such a sentence, three "local pragmatics" problems are identified: (A) What relation holds between Boston and the office? (B) How is the reference of "the Boston office" resolved? (C) What mechanism underlies the metonymy shift to "some person at the Boston office"?

The basic idea is expressed in the statement: "Solving local pragmatics problems is equivalent to proving the logical form plus the constraints." (Hobbs et al. 1993, p.72)

There is other recent work by A sher, Lascarides, and colleagues (Asher \& Lascarides 1995, Copestake \& Briscoe 1995, Lascarides \& Copestake 1995, Lascarides et al. 1996) that also goes seriously into the problem of how we call upon the masses of background knowledge when we have to choose just the relevant bits to use in a given discourse interpretation problem. Some of these works also begin to tackle the crucial problem of how linguistic and non-linguistic information, in the form of both hard constraints and soft preferences, is integrated in processing the kinds of examples we have been discussing. This remains one of the most important and difficult problem areas that must be developed in order to progress from plausible accounts of individual examples to predictive and explanatory accounts that have both solid theoretical foundations and the potential for robust applicability to a wide variety of linguistic expressions and non-linguistic contexts. The challenging problem of metonymy provides an excellent meeting ground for anticipated advances in the study of ontological domains underlying language in linguistics, psychology, and artificial intelligence, and for the integration of formal and functional approaches, and of theoretical and applied investigations.

O ur own work makes a small contribution to this enterprise from the linguistic side; but our approach using the idea of "text as theory" will not be fully testable unless and until it can be embedded in a larger framework that includes a substantive theory of 
natural language ontology and abductive or other methods for integrating relevant nonlinguistic knowledge with lexical and compositional semantic information, triggering metonymic and other shifts as appropriate.

\section{References}

Apresjan, J. D . 1974. Leksicheskaja Semantika. Sinonimicheskie Sredstva Jasyka. Moscow: Nauka.

Apresjan, J. D. 1986. D ejksis V Leksike I Grammatike I Naivnaja Model' Mira [D eixis in Lexicon and Grammar and the Naive Model of the World]. Semiotika i Informatika 28.

Apresjan, J. D . 1994. O Jazyke Tolkovanij I Semanticheskix Primitivax [on the Language of Lexical Explications and Semantic Primitives]. Izvestija Rossiskoj Akademii Nauk, Serija lit. i jasyka 53.

Apresjan, J. D ., Mel'chuk, I., \& Zholkovsky, A. 1969. Semantics and Lexicography: Towards a New Type of Unilingual Dictionary. In Studies in Syntax and Semantics, ed. Kiefer, F., 1-33. D ordrecht: Reidel.

Asher, N., \& Lascarides, A. 1995. Lexical Disambiguation in a Discourse Context. Journal of Semantics 12:69-108.

Bach, E. 1986a. The Algebra of Events. Linguistics and Philosophy 9:5-16.

Bach, E. 1986b. Natural Language Metaphysics. In Logic, Methodology, and Philosophy of Science Vii, eds. Marcus, R. B., D orn, G. J. W., \& Weingartner, P., 573-595. Amsterdam: North-Holland.

Bennett, M. 1974. Some Extensions of a Montague Fragment of English, University of California at Los Angeles: $\mathrm{PhD}$. dissertation; distributed by Indiana University Linguistics Club.

Bierwisch, M., \& Schreuder, R. 1992. From Concepts to Lexical Items. Cognition 42:2360.

Borschev, V., \& Partee, B. H. 1998. Formal and Lexical Semantics and the G enitive in Negated Existential Sentences in Russian. In Formal Approaches to Slavic Linguistics 6: The Connecticut Meeting 1997, eds. Boskovic, e., Franks, S., \& Snyder, W., 75-96. Ann Arbor: Michigan Slavic Publications.

Borschev, V., \& Partee, B. H. 1999a. Semantic Types and the Russian G enitive Modifier Construction. In Formal Approaches to Slavic Linguistics: The Seattle Meeting 1998, ed. al., K. D. e. Ann Arbor: Michigan Slavic Publications.

Borschev, V., \& Partee, B. H. 1999b. Semantika Genitivnoj Konstrukcii: Raznye Podxody K Formalizacii [Semantics of Genitive Construction: Different Approaches to Formalization]. In Tipologija I Teorija Jazy/ka: Ot Opisanija K Ob" Jasneniju. K 60-Letiju Aleksandra Evgen'evia Kibrika [Typology and Linguistic Theory: From Description to Explanation. For the 60th Birthday of Aleksandr E. Kibrik], eds. Rakhilina, E. V., \& Testelets, Y. G., 159-172. Moscow: Jazyki Russkoj K ul'tury.

Borschev, V. B. 1996. Estestvennyi Jazyk - Naivnaja Matematika D lja O pisanija Naivnoj Kartiny Mira [Natural Language as Naïve Mathematics]. Moscow Linguistic Almanac 1:203-225.

Borschev, V. B., \& Knorina, L. V. 1990. Tipy Realij I Ix Jazykovoe Vosprijatie [Types of Entities and Their Perception in Language]. In Language of Logic and Logic of Language, 106-134. Moscow.

Copestake, A., \& Briscoe, T. 1995. Semi-Productive Polysemy and Sense Extension. Journal of Semantics 12:15-67. 
Dölling, J. 1992a. Flexible Interpretation D urch Sortenverschiebung. In Fügungspotenzen, eds. Zimmermann, I., \& Strigin, A., 23-62. Berlin: Akademie Verlag.

Dölling, J. 1992b. Polysemy and Sort Coercion in Semantic Representations. In Discourse and Lexical Meaning: Proceedings of a Workshop of the Dfg Sonderforschungsbereich 340., eds. Bosch, P., \& Gerstl, P., 61-78. Stuttgart: Arbeitspapiere des Sonderforschungsbereich 340: "Sprachtheoretische Grundlagen für die Computerlinguistik".

Dölling, J. 1993. Commonsense O ntology and Semantics of Natural Language [1993]. Sprachtypol. Univ. Forsch. (STUF) 46:133-141.

Dölling, J. 1995. O ntological D omains, Semantic Sorts and Systematic Ambiguity. International Journal of Human-Computer Studies 43:785-807.

Dölling, J. 1997. Semantic Form and Abductive Fixation of Parameters. In From Underspecification to Interpretation, eds. van der Sandt, R., Blutner, R., \& Bierwisch, M., 113-138. Heidelberg: IBM D eutschland.

Heim, I., \& Kratzer, A. 1998. Semantics in Generative Grammar. London: Blackwell.

Hobbs, J. R., Stickel, M. E., Appelt, D . E., \& Martin, P. 1993. Interpretation as Abduction. Artificial Intelligence 63:69-142.

Jackendoff, R. S. 1997. The Architecture of the Language Faculty: Linguistic Inquiry Monographs ; 28. Cambridge, Mass.: MIT Press.

Jensen, P. A., \& Vikner, C. 1994. Lexical Knowledge and the Semantic Analysis of D anish G enitive Constructions. In Topics in Knowledge-Based Nhp Systems, eds. S.L.Hansen, \& H.Wegener, 37-55. Copenhagen: Samfundslitteratur.

Knorina, L. V. 1985. Ob Interpretacii G enitivnyx Konstrukcij [on the Interpretation of Genitive Constructions]. In Theses of the Workshop "Semiotic Foundations of Intellectual Activity. Moscow: VINITI.

Knorina, L. V. 1988. Klassifikacija Leksiki I Slovarnye D efinicii [Lexical Classification and Dictionary Definitions]. In Nacional'naja Specifika Jasyke I Ee Otrą̌Enie V Normativnom Slovare, ed. Karaulov, J. N., 60-63. Moskva: Nauka.

Knorina, L. V. 1989. G entivnye Sravnenija V Poezii Pasternaka [G enitive Similes in the Poetry of Pasternak]. Stilistika i poetika [Stylistics and Poetics].

Knorina, L. V. 1990. Narushenija Sochetajemosti I Raznovidnosti Tropov V G enitivnoj Konstrukcii [Violations of Cooccurrence and Varieties of Tropes in $\mathrm{G}$ enitive Construction]. In Contradictions and Anomalies of Text, 115-124. Moscow.

Knorina, L. V. 1996. The Range of Biblical Metaphors in Smikhut. Moscow Linguistic Journal 3:80-94.

Kratzer, A. 1994. The Event Argument and the Semantics of Voice. Ms. UMass Amherst.

Kratzer, A. 1995. Stage-Level and Individual-Level Predicates. In The Generic Book, eds. Carlson, G. N., \& Pelletier, F. J., 125-175. Chicago: The University of Chicago Press.

Krifka, M. 1995. Common Nouns: A Contrastive Analysis of Chinese and English. In The Generic Book, eds. Carlson, G. N., \& Pelletier, F. J., 383-411. Chicago: The University of Chicago Press.

Lascarides, A., \& Asher, N. 1993. Temporal Interpretation, Discourse Relations and Commonsense Entailment. Linguistics and Pbilosophy 16:437-493.

Lascarides, A., \& Copestake, A. 1995. The Pragmatics of Word Meaning. In Proceedings from Salt $V$, eds. Simons, M., \& Galloway, T., 204-221. Ithaca: Cornell University.

Lascarides, A., Copestake, A., \& Briscoe, T. 1996. Ambiguity and Coherence. Journal of Semantics 13:41-66. 
Link, G. 1983. The Logical Analysis of Plurals and Mass Terms: A Lattice-Theoretical Approach. In Meaning, Use and the Interpretation of Language, eds. Bäuerle, R., Schwarze, C., \& von Stechow, A., 303-323. Berlin, New Y ork: Walter de G ruyter. Reprinted in Link, G odehard. 1998. Algebraic Semantics in Language and Philosophy: CSLI lecture notes No. 74. Stanford, Calif.: CSLI Publications. pp.11-34. Montague, R. 1973. The Proper Treatment of Q uantification in O rdinary English. In Approaches to Natural Language, eds. Hintikka, K. J. J., Moravcsik, J. M. E., \& Suppes, P., 221-242. D ordrecht: Reidel. Reprinted in Montague 1974, 247-270

Parsons, T. 1985. Underlying Events in the Logical Analysis of English. In Actions and Events: Perspectives of the Philosophy of Donald Davidson., eds. LePore, E., \& McLaughlin, B., 235-267. O xford: Blackwell.

Parsons, T. 1990. Events in the Semantics of English. A Study in Subatomic Semantics. Cambridge MA: MIT Press.

Partee, B. 1997. G enitives - a Case Study [Appendix to Theo Janssen's Chapter "Compositionality"]. In Handbook of Logic and Language, eds. Benthem, J. v., \& Meulen, A. t., 464-470. Amsterdam: Elsevier.

Partee, B. H., \& Borschev, V. B. 1998. Integrating Lexical and Formal Semantics: G enitives, Relational Nouns, and Type-Shifting. In Proceedings of the 2nd Tbilisi Symposium on Language, Logic, and Computation, eds. Cooper, R., \& G ramkrelidze, T., 229-241. Tbilisi: Center on Language, Logic, Speech, Tbilisi State University.

Partee, B. H., \& Borschev, V. B. 2000. G enitives, Relational Nouns, and the ArgumentModifier Distinction. In Zas Papers in Linguistics 17, eds. Fabricius-Hansen, C., Lang, E., \& Maienborn, C., 177-201. Berlin: Zentrum für Allgemeine Sprachwissenschaft, Sprachtypologie und Universalienforschung.

Partee, B. H., \& Borschev, V. 2001. Some Puzzles of Predicate Possessives. In Perspectives on Semantics, Pragmatics and Discourse. A Festschrift for Ferenc Kiefer., eds. Kenesei, I., \& Harnish, R. M., 91-117. Amsterdam: John Benjamins.

Pustejovsky, J. 1993. Type Coercion and Lexical Selection. In Semantics and the Lexicon, ed. Pustejovsky, J., 73-94. D ordrecht: Kluwer.

Pustejovsky, J. 1995. The Generative Lexicon. Cambridge, Mass.: MIT Press.

Rothstein, S. ed. 1998. Events and Grammar. vol. 70. Studies in Linguistics and Philosophy. D ordrecht: Kluwer Academic Publishers.

Tenny, C., \& Pustejovsky, J. eds. 2000. Events as Grammatical Objects: The Converging Perspectives of Lexical Semantics, Logical Semantics and Syntax. vol. 100. Csli Lecture Notes. Stanford: CLSI Publications.

Vikner, C., \& Jensen, P. A. 1999. A Semantic Analysis of the English Genitive: Interaction of Lexical and Formal Semantics. Ms. Copenhagen and Kolding, D enmark.

Williams, E. 1981. Argument Structure and Morphology. The Linguistic Review 1:81-114. 